\title{
Investigations of Latrine Coverage and Associated Factors Among Debretabor Town, Amhara Region North West Ethiopia
}

\author{
Yilkal Tafere $^{1}$, Mirkuzie Woldie ${ }^{2}$, Henok Assefa ${ }^{3}$ \\ ${ }^{1}$ Department of public health, Debretabore University, Debre Tabor, Ethiopia \\ ${ }^{2}$ Department of Health Services Management, Jimma University, Jimma, Ethiopia \\ ${ }^{3}$ Department of Epidemiology and Biostatistics, Jimma University, Jimma, Ethiopia
}

\section{Article Info}

Article history:

Received Dec 15, 2015

Revised Feb 16, 2016

Accepted Apr 29, 2016

\section{Keyword:}

Educational status

Ethiopia

Health service program

Latrine coverage

Structured questionnaire

\begin{abstract}
Studies in a number of countries have shown that wherever inappropraite waste disposal morbidity and mortality rates are high. Although latrine coverage is an important indicator for measuring success of the health service program; data on latrine coverage scarce in the study area. To investigate latrine coverage and associated factorsinamong households of Debretabor town, Amhara region, Ethiopia. A community based cross sectional study was conducted in Debretabor town from September 1-30, 2013. A total of 422 households were included in the study using systematic sampling technique. Data were collected using structured questionnaire and analyzed using SPSS version 16.0. Degree of association between independent and dependent variables was assessed with a $95 \%$ confidence level and p-value less than 0.05 was used to detect statistical significance. In this study. Ninety three point five percent of households have latrine. Graduated as model family was predictor for availability of latrine ( $\mathrm{AOR}=3.18$,). Income and house ownership were also found to be predictors for availability of latrine (AOR=3.70), $(\mathrm{AOR}=8.46)$, respectively. Educational status of respondents was found to be predictors for availability of latrine $(\mathrm{AOR}=2.65)$. Latrine coverage was relatively lower from the national target of $100 \%$, still there are households that use open defication. Educational status, house owner shipe, income and graduated as model family were main factors affecting latrine availability. Improving socio economic status of households, provision of continuous advice and technical support at household level on the availability of latrine are recommended.
\end{abstract}

Copyright (C) 2016 Institute of Advanced Engineering and Science. All rights reserved.

Corresponding Author:

Yilkal Tafere,

Department of Public Health,

Debretabore University,

Debre Tabor, Ethiopia.

Email: yilkal2007@yahoo.com

\section{INTRODUCTION}

Creating proper waste management practices is an essential part for improved human health. In Ethiopia waste management practices coverage remain low $(60 \%)$ even substantial efforts is made by the government. In general, sanitation related health risks are common problems [1] According to study on 444 HHs of Kersa woreda, Ethiopia, showed that only 156 (36.4\%) HHs reported that they have latrine [2].

Ethiopian population has poor health status, low income and education level especially among the women, inadequate access to sanitation facilities contribute to the burden ill health. The health challenges facing Ethiopia are substantial. Maternal mortality ratio in Ethiopia is (MMR) 676/100,000 live births. This 
indicates that need for expansion of primary health care facilities in order to attain universal health coverage [3].

Urban environments are more likely to see large differences in socioeconomic status. In Ethiopia as elsewhere in developing countries, urban dwellers often lack basic sanitation. Lack of basic infrastructure can exacerbate rates of infectious disease [4],[5].

Improper excreta disposal are principal determinants for both morbidity and mortality. It is estimated that more than five million people die each year from diseases related to inappropriate waste disposal [6]. Moreover, $88 \%$ of diarrheal diseases are attributed to poor sanitation [7]. In the 48 countries designated as the least developed by the United Nations, 1 in 4 people practice open defecation [8].

In developing countries waste management often emerges as a problem that endangers human health. To make matters worse, waste management usually has a low priority on the political program of such countries, as they are struggling with other important issues [9]. A massive disease burden is associated with deficient sanitation and is largely preventable with proven, cost-effective interventions [10].

In the last few years in many areas of Ethiopia urban population growth is increasing. Urban areas are among the worst in waste management because of this health related problems are rising. Much of these wastes, which lead to high rates of disease and death, are caused by lack of adequate excreta disposal facilities. As population increase, the situation will grow worse and the need for safe and affordable sanitation technology at HHs level will be more critical. Although urban sanitation facility figures generally are more than rural, it is widely known that the poor, unplanned, densely populated areas are underserved. This density therefore poses a great risk of contamination. Limited sanitation options and high demand are compounded by poverty and limited space, creating a major challenge unmet waste disposal needs of the urban poor who resort to high-risk excreta disposal practices [5],[11].

In most of developing countries including Ethiopia waste management practices are poor. Sanitation Coverage in Ethiopia remain low $(60 \%)$ even considerable efforts is made by the government, sanitation related health risks are common problems it is and associated with low sanitation coverage [1]. Although the government of Ethiopia tries to solve urban health problems through Urban Health Extension Package UHEP; there are issues in waste management practices that affect urban population, only $14 \%$ urban population has acces to an improved toilet [12].

A study conducted in the District of Bahir Dar Zuria shows that availability of latrines was twice higher in HHs with an income of 5000 or more Ethiopian Birr per year [13]. Another study in SNNPR; indicate that $77 \%$ HHs reported that discussion was made with HEWs on latrine utilization [14]. A study done in Dukem, Ethiopia, 2011 shows tha 55\% of HHs had latrine. Availability of latrin was significantly associated with house ownership $(\mathrm{p}<0.05)[15]$.

In Ethiopia, even though progress was made in reducing child mortality from 123 deaths of under five years of children per 1,000 live births in 2005 [16] to 88 deaths per 1,000 live births in 2011[3], children in the country still suffer from diarrheal diseases. According to Ethiopian demographic and health survey, the two week prevalence of diarrheal diseases was $13 \%$ among under five children [3].

To improve sanitation throughout Ethiopia, the National Sanitation Strategy establishes the goal of $100 \%$ latrine coverage [17]. The construction of sanitation facilities is underway in all parts of the country since the introduction of the HEP by the ministry of health. Because of growing concerns of improper excreta disposal related health risks from the towns of the country, it is essential to perform community based studies that will support better understanding of the problems. Based on these contexts, the present study was conducted with regard to Investigations of latrine coverage and identified the factors that affect latrine coverage among households of Debretabor town, Northwest Ethiopia.

\section{RESEARCH METHOD}

Community based cross-sectional study was conducted in Debre tabor town, North West Ethiopia from September 1-30/2013. Debre tabor town is located $665 \mathrm{Kms}$ away from Addis Ababa, capital of Ethiopia. Study Population was selected HHs found in Debretabor town during the study period. Individual household heads that lives in the town for at least 6 months and above during the study period was included. Availability of latrine was dependent variable. Marital status, Educational status, Religion, Family size, Monthly family income of respondents to UHEP, graduated as amodel family were independent variables.

Sample size was calculated using single population proportion formula. By taking the proportion of waste disposal coverage of households, 53.3\%, from other studies [15]. Confidence interval at $95 \%$ and setting alpha at 5\%, 422 total of sample size was calculated. The sample size was allocated proportional to the size of households in each kebele (the smallest administrative unit in Ethiopia). The number of 
households was taken from each kebele administrative office. The first household was selected by lottery method and the subsequent households were selected using systematic sampling technique.

Data were collected using a structured questionnaire adopted from reviewing literatures. Eight data collectors and one supervisor were recruited and face to face interview was the technique of data collection. Data collection tools were initially prepared in English and were translated in to Amharic (local language) and again re-translated back to English.

To assure quality, data collectors and their supervisor were trained for two days and pretesting of the instrument was conducted before the actual data collection. The data were entered into EPI Info version 3.1 and exported to SPSS version 16.0 statistical software for its analysis. Both bivariate and multivariable analyses were done. All variables with a p-value $<0.25$ in the bivariate analysis were further fit to multivariable logistic regressions for better prediction of determinants. Crude and adjusted odds ratio with $95 \%$ confidence intervals were computed. P-value less than 0.05 was taken as statistically significant.

The study was ethically approved by research ethical committee review board of Jimma University. Before commencing data collection legal permission with letter of support was obtained from Debre Tabor town health office. All the study participants were informed about the purpose of the study and their right to refuse. Informed consent was obtained from every respondent. Strict confidentiality was also maintained through coding of questionnaire anonymously.

\section{RESULTS AND ANALYSIS}

A total of 422 households sampled in the town and 414 of them have participated in this study. From total study subjects were $337(81.4 \%)$ females. The mean age was 35.99 with \pm 9.23 year standard deviation. Majority of respondents $281(67.9 \%)$ were married, and $158(38.2 \%)$ were housewives respectively. The mean family size of the households was 3.62. Regarding the ethnicity $401(96.9 \%)$ of the respondent were Amhara and majority of the respondents 373 (90.1\%) were Orthodox by religion. More than three forth of households $314(75.8 \%)$ were privately owned. About three hundred twenty six (78.7\%) of the respondents attended formal education and only less than half, 179 (43.2\%) households were graduated as a model family. As Table 1, from the total 414 households, 387(93.5\%) HHs do have latrine, among these $353(91.2 \%)$ of them have private latrine while the rest $34(8.8 \%)$ of the latrines were shared. Among the households who did not have their own toilet $21(77.8 \%)$ of them used open field to defecate. Regarding the type of latrine $350(90.4 \%)$ were pit latrine, $24(6.2 \%)$ ventilated improved pit latrine, $13(3.4 \%)$ water carriage. Out of the total household toilets, 347 (89.7\%) toilets were functional during visit.

Table 1. Availability of latrine among the respondents in Debretabor town, Amhara Region, North West of Ethiopia, September 2013

\begin{tabular}{|c|c|c|c|}
\hline \multirow{3}{*}{ Availability of toilet facility } & & Frequency & Percent $(\%)$ \\
\hline & Yes & 387 & 93.5 \\
\hline & No & 27 & 6.5 \\
\hline \multirow[t]{3}{*}{ Do you share your private toilet with other households } & Yes & 34 & 8.8 \\
\hline & No & 353 & 91.2 \\
\hline & Total & 387 & 100.0 \\
\hline \multirow[t]{3}{*}{ The status of latrine during the visit } & Functional & 347 & 89.7 \\
\hline & Not functional & 40 & 10.3 \\
\hline & Total & 387 & 100.0 \\
\hline \multicolumn{4}{|l|}{ Reasons for not having private latrine } \\
\hline \multirow[t]{3}{*}{ Lack of adequate space } & Yes & 4 & 14.8 \\
\hline & No & 23 & 85.2 \\
\hline & Total & 27 & 100 \\
\hline \multirow[t]{3}{*}{ Land unsuitable to construct latrine } & Yes & 1 & 3.7 \\
\hline & No & 26 & 96.3 \\
\hline & Total & 27 & 100 \\
\hline \multirow[t]{3}{*}{ Financial problem } & Yes & 15 & 55.6 \\
\hline & No & 12 & 44.4 \\
\hline & Total & 27 & 100 \\
\hline \multirow[t]{3}{*}{ The house is rented } & Yes & 12 & 44.4 \\
\hline & No & 15 & 55.6 \\
\hline & Total & 27 & 100 \\
\hline \multirow{3}{*}{$\begin{array}{l}\text { If your HHs do not have private latrine, where do you } \\
\text { usually use? }\end{array}$} & Open field & 21 & 77.8 \\
\hline & Share neighbor toilet & 6 & 22.2 \\
\hline & Total & 27 & 100.0 \\
\hline
\end{tabular}




\subsection{Factors associated with availability of latrine}

During the bivariate analysis, house ownership, income, educational status, being graduated as model family were the variables that was found to be significantly associated with availability of latrine at significance level of $\mathrm{p}$-value $\leq 0.25$.

All the variables which show significant association during the bivariate analysis were entered to multivariable ananysis, house ownership, income, educational status, being graduated as model family show significant association at $\mathrm{p}$-value $<0.05$.

Educational status also shows significant association with availability of latrine Respondents who attended any level of education were about 2.65 times more likely to have latrine than those who do not attended $(\mathrm{AOR}=2.65 ; 95 \% \mathrm{CI}=1.06,6.63)$. In this study, Respondents who had their own house were 8.46 more likely to have latrine than those who rent the house ( $\mathrm{AOR}=8.46 ; 95 \% \mathrm{CI}=3.36,21.33)$.

Similarly respondents who had an income of 1201 or more Eth.Birr per month were 3.70 more likely to have latrine than respondents with or less than 1200 Eth Birr per month (AOR=3.70; 95\% $\mathrm{CI}=1.17,11.71)$. Households who graduated as model family on HEP were 3.18 more likely to have latrine than respondents who were not graduated as model family on HEP (AOR, 3.18; 95\% CI=1.16, 8.67), as Table 2 .

Table 2. Association of sociodemographic and other characteristics of respondents with latrine availability in Debretabor town, Amhara, North Wast Ethiopia, Sep 2013

\begin{tabular}{|c|c|c|c|c|}
\hline \multirow{2}{*}{ Variables } & \multicolumn{2}{|c|}{ Availability of latrine } & \multirow{2}{*}{$\operatorname{COR}(95 \% \mathrm{CI})$} & \multirow{2}{*}{$\operatorname{AOR}(95 \% \mathrm{CI})$} \\
\hline & Yes $(\%)$ & No $(\%)$ & & \\
\hline \multicolumn{5}{|l|}{ Owner ship of the house } \\
\hline Private & $307(97.8)$ & $7(2.2)$ & $10.96(4.48,26.84)$ & $8.46(3.36,21.33)^{* *}$ \\
\hline Rent from private & $80(80.0)$ & $20(20.0)$ & 1 & \\
\hline \multicolumn{5}{|l|}{ Monthly income (ETB) } \\
\hline$<=1200$ & $186(89.0)$ & $23(11.0)$ & 1 & \\
\hline$>=1201$ & $201(98.0)$ & $4(2.0)$ & $6.21(2.11,18.30)$ & $3.70(1.17,11.71)^{*}$ \\
\hline \multicolumn{5}{|l|}{ Educational status } \\
\hline Never attended school & $76(86.4)$ & $12(13.6)$ & 1 & \\
\hline Attended some school & $311(95.4)$ & $15(4.6)$ & $3.27(1.47,7.28)$ & $2.65(1.06,6.63)^{*}$ \\
\hline \multicolumn{5}{|c|}{ Being graduated as model family } \\
\hline Yes & $173(96.7 \%)$ & $6(3.4 \%)$ & $2.81(1.12,7.17)$ & $3.18(1.16,8.67)^{*}$ \\
\hline No & $214(91.1 \%)$ & $21(8.9 \%)$ & 1 & 1 \\
\hline
\end{tabular}

\subsection{Discusion}

This study was conducted to investigate availability of latrine and associated factors in Debretabor town, Amhara, North West Ethiopia. The findings of this study showed that $93.5 \%$ of the HHs had latrines. This result is almost similar with a study done in Damboy woreda, SNNPR, and Dukem town, Ethiopia 2011 that, $93.8 \%$ and $91.3 \%$ HHs had latrine facility respectively [14], [15]. This similarity might be in both of the study areas the presence of health extension workers might contribute for the availability of latrine .Out of those who did not have their own latrines, about $77.8 \%$ of them were using open defecation. This indicates a need to sustainable and multistrategy promotion.

The effect of other factors on availability of latrine was assessed. House ownership was significantly associated with availability of latrine. Respondents who had their own house were 8.46 times more likely having latrine. This finding is inline with the findings of a study done in Damboya Woreda, Dukem town and Kersa [2], [14-15]. This similarity might be in both study areas since respondents had their own house it might be suitable to construct latrine by arranging their premises. So that people can outweigh the benefits of availability of latrine and they can keep the surroundings clean considering that they are living permanently in the area.

Educational status of the respondents was also found to be an important predictor for availability of latrine. This could be due to education leads to increase awareness to bring behavioral change about the benefit of availability of latrine.

Findings from this study showed that income of the respondents was found to have statistically significant association with availability of latrine Those respondents who had an income of 1201 and more Eth.Birr per month were 3.70 more likely to have latrine than respondents with or less than 1200 Eth Birr . This report is consistent with the study done in Zuriya [13].

IJPHS Vol. 5, No. 2, June 2016: $137-141$ 


\section{CONCLUSION}

In this study even though there was a higher percentage of latrine coverage in the studied households' $100 \%$ latrine coverage was not achieved during the time of data collection. The findings of this study have important implication for improving availability of latrine. Health planners need to understand possible determinant factors at the household level which affects availability of latrine. Educational status, house ownership, income, graduated as model families on UHEP were factors that affect the availability of latrine.

\section{ACKNOWLEDGEMENTS}

We would like to express our grateful heartfelt appreciation to Debre tabor Town Administrators, data collectors and supervisors of the study for their cooperation and support, giving unreserved time and follow up from the beginning till completion of this research .Our acknowledgement also extends to study participants who were involved in this study.

\section{REFERENCES}

[1] FMOH, "Community led sanitation and hygiene (CLTSH) verification and certification protocol," Addis Ababa Ethiopia, 2012.

[2] Bizatu M. \& Negga B., "Community based assessment on household management of waste and hygiene practices in Kersa Woreda, Eastern Ethiopia," Ethiop. J. Health Dev, vol/issue: 24(2), pp. 104-109, 2008.

[3] Central Statistical Agency [Ethiopia] and ICF International, "Ethiopia Demographic and Health Survey," Addis Ababa, Ethiopia and Calverton, Maryland, USA: Central Statistical Agency and ICF International, 2012.

[4] "Urban Versus Rural Health," Available from: URL: http://www.uniteforsight.org/global-health-university/urbanrural-health.

[5] FMOH, "Urban health extension package implementation guide line," 2009.

[6] J. K. Tumwine, et al, "Diarrhea and effects of different water sources, sanitation and hygiene behavior in East Africa," Trop Med Int Health, WHO, vol/issue: 7(9), pp. 750-756, 2007.

[7] World Health Organization, "WHO Facts and figures: Water, sanitation and hygiene links to health," 2004.

[8] WHO/UNICEF, "Progress on drinking water and sanitation," 2012.

[9] H. B. N. Yongsi, et al., "Environmental Sanitation and Health Risks in Tropical Urban Settings: Case Study of Household Refuse and Diarrhea in Yaoundé Cameroon," International Journal of Human and Social Sciences, 2008.

[10] Bartram J. \& Cairncross S., "Hygiene, Sanitation, and Water: Forgotten Foundations of Health,” PLoS Med, 2010.

[11] F. Kebede, et al., "Lecture notes for Environmental Health Students, Human and Other Liquid Waste Management," Jimma University, 2002.

[12] USID/Ethiopia, "End of project Evaluation for urban health extension program April," 2012.

[13] Awoke W. \& Muche S., "A cross sectional study: latrine coverage and associated factors among rural communities in the District of Bahir Dar Zuria, Ethiopia," BMC Public Health, vol. 13, pp. 99, 2013.

[14] Korma S., "Assessment of the extent of implementation and affecting factors of environmental health extension packages at house hold level in Damboya Woreda, Kembata Zone, SNNP Region,” 2011.

[15] Mohammed A., "Assessing environmental sanitation in urban setting of Dukem Town, Ethiopia, University Of South Africa," 2011.

[16] Central Statistical Agency [Ethiopia] and ORC Macro, "EDHS 2005," Addis Ababa, Ethiopia and Calverton, Maryland, USA: Central Statistical Agency and ORC Macro, 2006,

[17] Ministry of Health, "National Hygiene and Sanitation Strategy," Addis Ababa Ethiopia, 2005. 